\title{
Study on the structure and hydraulic performance of the hydraulic pressure emitter of reverse gear
}

\author{
Fang Buling $^{1, a}$, Qi Songtao ${ }^{2, b}$, Wu Shaojie $^{3}$,Wang Zi $^{4}$, Li Ruixian $^{5}$ \\ ${ }^{1}$ Key Laboratory of Efficient Irrigation-Drainage and Agricultural Soil-Water Environment in \\ Southern China, Hohai University, Nanjing 210098, China \\ 2 Jiangsu JiuShu Electromechanical Technology Co., Ltd, Nanjing 210002, China \\ 3 Jilin Guoyuan Construction Engineering Design Co., Ltd.Changchun 130000 China. \\ afbling@163.com, ${ }^{b} 54741469 @ q q . c o m$
}

Keywords: emitter; flow structure; micro pressure; drip irrigation

\begin{abstract}
With the shortage of water resources in China, water-saving agriculture has been highly addressed and developed by the government. This paper studies the channel structure of a helical micro pressure drip irrigation emitter, focusing on the tilt and tooth chamfer's angles within eight different combinations of structure parameters. By comparison of hydraulic performances, it show a small discrepancies between CFD software simulating results and testing results on 6 selected real trial prototype samples of flaky emitters and inlaid drip pipes. A conclude is made that under various flow coefficient $\mathrm{K}$ and pressure sensitive coefficient $\mathrm{X}$, in the section of minimum flow, the smaller angle $\theta$ the better hydraulic performance, the bigger angle $r$ the better anti clogging ability.
\end{abstract}

\section{Introduction}

Our country is lacking water resources and is in the list of 13 world's water resource poor countries. The water-saving irrigation in China is still under-developed as the advanced water-saving irrigation technology coverage is less than $10 \%$. The national loses water resources up to nearly 2000 billon $\mathrm{m}^{3}$ annually, and efficiency of agricultural water using is low, therefore there is upside potential ${ }^{[1] . ~ D r i p ~ i r r i g a t i o n ~ t e c h n o l o g y ~ i s ~ a n ~ a d v a n c e d ~ t e c h n o l o g y ~ f o r ~ e n e r g y ~ s a v i n g ; ~ i t ~}$ increases production and efficiency. While there are many factors restricting the development of drip irrigation, the expensive investment in drip irrigation system is one of the main obstacles to promote the technology. Pressure is the most important factor determining the price of drip irrigation system; through reducing the pressure, the equipment price would be more feasible, while not decreasing the quality of irrigation ${ }^{[2]}$. The quality of drip irrigation system and work reliability to a large extent determine emitter (also known as the dripper) performance and how they work, so domestic and foreign focus have been placed on emitter development and the main direction of research is based on the anti blocking and steady flow hydraulics, structure design and irrigation effect ${ }^{[3]}$. Therefore, it is important to design a new drip irrigation emitter with better performance under the condition of micro pressure, which will be of great significance for the development of water-saving agriculture and drip irrigation technology.

This paper (of authors are member of Water Saving Special Sections of Nation 863 program), based on the principle of small water usage, stable water flow, durable and inexpensive, studies a helical pressure drip irrigating flow channel with 8 new designed types of micro pressure drip irrigation emitters. Based on simulating results by using the sophisticated CFD (computational selected six designs are manufactured with small amount samples. Samples are carefully examined under microscope to make sure they are satisfied design requirements,. By comparing the lab fluid dynamics) software, 6 designs are selected of which having better performances. The performance test and computer theoretical analysis and simulation results, the performances are evaluated from samples and theoretical simulating to predict the impacts of structure parameters. 


\section{Design of flow channel structure of the inclined tooth micro pressure drip irrigation emitter}

The helical gear micro pressure drip irrigation emitter channel is designed as, with an straight line or circular boundary from top to bottom within a certain depth of pass through flow passage channel. The flow channel structure is designed as intersected helically, so the inclination angle of the flow channel can be changed from 0 to the side of the center line of the channel in order to improve the anti clogging ability of emitter ${ }^{[5]}$.

Its flow channel structure is shown in the opinion Figure 1.1

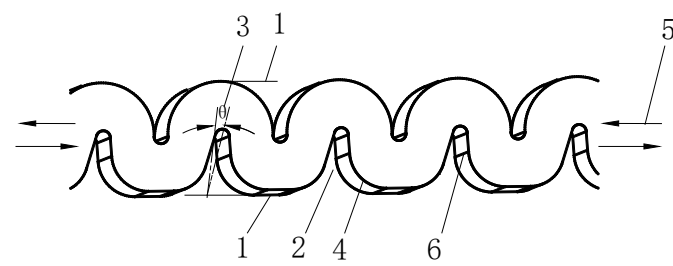

1.flow channel boundary; 2.channel tooth;

3. tooth angle $\theta$; $\quad$ 4. fillet chamfer;

5. the flow of water in the direction of the flow;

6. channel depth;

Fig. 1.1 schematic diagram of the structure of the inclined tooth micro pressure drip irrigation emitter

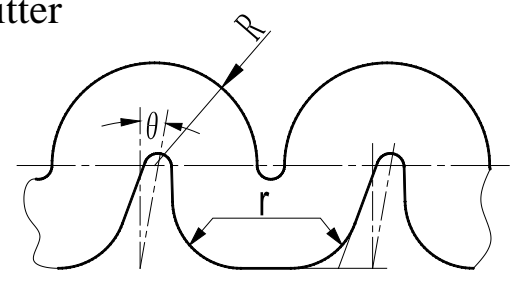

Figure 1.3 oblique tooth side of the border is semi-circular, side line

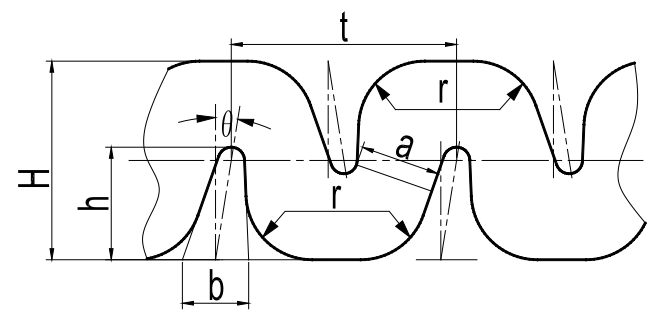

Fig. 1.2 the upper and lower boundary of the oblique teeth is linear

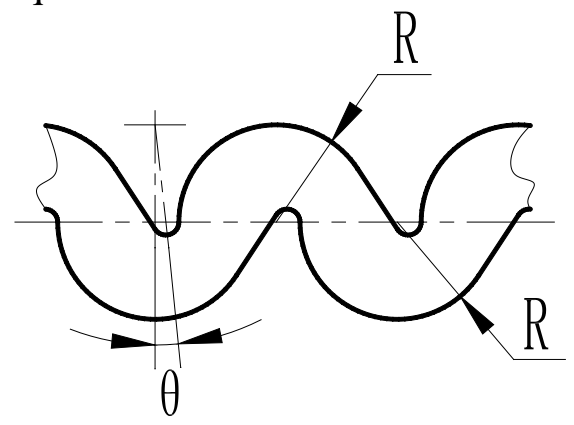

Figure 1.4 helical upper and lower boundary are semi-circular

Figure. 1.2 the upper and lower boundary of the oblique teeth is linear; Figure 1.3 oblique tooth side of the border is semi-circular, side line; Figure 1.4 helical upper and lower boundary are semi-circular.

By taking the approach of making the tine angle $\theta$ and the tooth root fillet $r$ as a channel tooth construction factors, we use CFD (computational fluid dynamics) software to simulate labyrinth dripper flow within changing the primary flow structure of tooth inclination angle $\theta$ and the tooth root fillet $r$ to study the influences of the hydraulic performances. The channel's tooth tips are intersected each others, instead of alignment in the same level. To eliminate the performance's impacts of other factors, make channel length $\mathrm{L}$, depth $\mathrm{D}$, width $\mathrm{h}$, the tooth pitch $\mathrm{T}$, tooth height with identical dimensions. Here the channel length refers the length from intake to output while tooth angle $\theta$ selected as 0 degrees, 5 degrees, 10 degrees, 15 degrees and tooth chamfer $r$ based on the size of tooth inclination angle $\theta$ with three values: $0.3,0.5$ and 0.8 accordingly $^{[4]}$. This paper proposes three tooth shape boundary structures: JJ as shown in Figure 1.2, JY as shown in figure 1.3. and YY as shown in figure 1.4. Within new channel structures of the arc and a straight line tooth combination, there are total of 8 different flow channel shape combinations. Computational fluid dynamics (CFD) simulation of channel internal flow can be used to predict its hydraulic performance and to determine its hydraulic performance. 6 designs are selected to create the real samples. To find out the structure performance parameters, the hydraulic performances on those samples are tested and compared with theoretical simulating result. Design values and codes of 8 types of flow channel structure characteristic parameter as Table 1.1. 
Table 1.1 the structure code and feature size of the micro pressure drip irrigation emitter

\begin{tabular}{cccccc}
\hline $\begin{array}{c}\text { Serial } \\
\text { number }\end{array}$ & Code & $\begin{array}{c}\text { tooth tip tilt } \\
\text { angle } \theta\left({ }^{\circ}\right)\end{array}$ & $\begin{array}{c}\text { Tooth } \\
\text { chamfer } \mathrm{r} \\
(\mathrm{mm})\end{array}$ & $\begin{array}{c}\text { Minimum } \\
\text { channel width } \\
\mathrm{a}(\mathrm{mm})\end{array}$ & $\begin{array}{c}\text { Minimum flow area } \\
\mathrm{A}\left(\mathrm{mm}^{2}\right)\end{array}$ \\
\hline 1 & JJ9r0.8 & 9 & 0.8 & 0.72 & 0.54 \\
2 & JJ15r0.8 & 15 & 0.8 & 0.70 & 0.525 \\
3 & JY0r0.3 & 0 & 0.3 & 0.76 & 0.57 \\
4 & JY5r0.5 & 5 & 0.5 & 0.76 & 0.57 \\
5 & JY10r0.8 & 10 & 0.8 & 0.75 & 0.563 \\
6 & JY15r0.8 & 15 & 0.8 & 0.73 & 0.548 \\
7 & JY15r0.5 & 15 & 0.5 & 0.73 & 0.548 \\
8 & JY15r0.3 & 15 & 0.3 & 0.73 & 0.548 \\
\hline
\end{tabular}

Simulation of CFD on micro pressure drip irrigation channel with inclined tooth

\section{A CAD 3D irrigator mode}

Pro/Engineer 3D design software is used in this paper.

The JY5r0.5 emitter flow channel as shown in Figure 2.2, the flow passage shape is shown in figure 2.1. This paper will start from the study on the inverted tooth (i.e. the water from flowing into the direction of tooth angle), simulation and real samples.

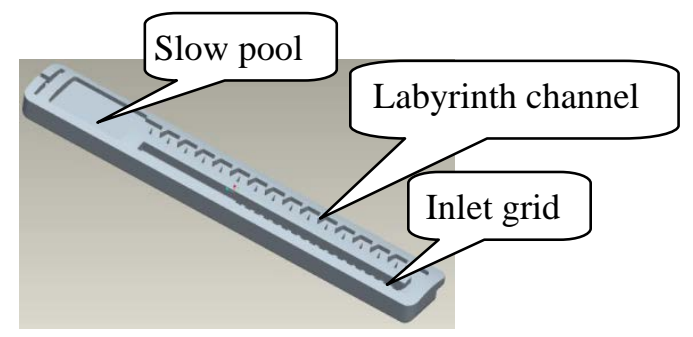

Figure 2.1 JY5r0.5Emitter Pro/E structure modeling

\section{B Analysis and digital simulation of fluid flow in the flow passage}

In this paper, computational fluid dynamics (CFD) software is used to simulate the software, which includes two parts: Gambit software and 6.1.22 Fluent software. Along with the development of computer technology, several calculating methods have been introduced: finite difference method, finite element method and finite volume method. ${ }^{[6,7]}$. The software Fluent used by the paper is the third method finite volume method. Finite volume method also is referred as controlled volume method. The node can be referred as a controlled volume which as a physic definition to be stored in the node during desecrating processing..The software Gambit is used to generate network model can be imported to Fluent to resolve fluid computing and analyzing.

\section{Grid division}

Fluent provides a very flexible grid features, including triangles, quadrilaterals, tetrahedron and hexahedron grid. The paper uses mixed grid with total 400k grids pre-processed by Gambit with size of 0.08 per unit. No visible changes when smaller unit selected. JY5r0.5 flow channel mesh is shown in figure 2.2 and figure 2.3。

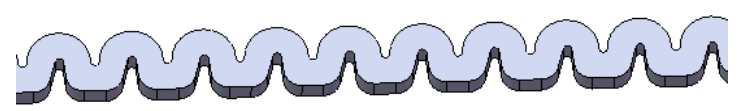

Fig. 2.2 Pro/E model of JY5r0.5 emitter

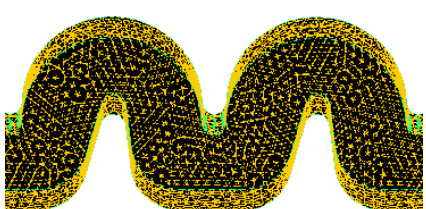

Fig. 2.3. JY5r0.5 flow channel mesh enlarged

\section{Mathematical model of simulation}

The function of drip irrigation emitter is to make water through various curved labyrinth channel, losing the energy, to become water dripper to irrigate the plants, fluid is water. Based on the feature of water as incompressible fluid, the fluid in channel conform law of conservation of mass and law of conservation of momentum. Under Cartesian coordinates system ${ }^{[6]}$

Mass conservation equation(continuous equation) is: $\frac{\partial u}{\partial x}+\frac{\partial v}{\partial y}+\frac{\partial w}{\partial z}=0$

Momentum conservation equation (Navier-Stokes equation) is: 


$$
\begin{aligned}
& \frac{\partial(\rho u)}{\partial t}+\frac{\partial(\rho u u)}{\partial x}+\frac{\partial(\rho u v)}{\partial y}+\frac{\partial(\rho u w)}{\partial z}=\frac{\partial}{x}\left(\mu \frac{\partial u}{\partial x}\right)+\frac{\partial}{y}\left(\mu \frac{\partial u}{\partial y}\right)+\frac{\partial}{z}\left(\mu \frac{\partial u}{\partial z}\right)-\frac{\partial p}{\partial x}+F_{x} \\
& \frac{\partial(\rho v)}{\partial t}+\frac{\partial(\rho v u)}{\partial x}+\frac{\partial(\rho v v)}{\partial y}+\frac{\partial(\rho v w)}{\partial z}=\frac{\partial}{x}\left(\mu \frac{\partial v}{\partial x}\right)+\frac{\partial}{y}\left(\mu \frac{\partial v}{\partial y}\right)+\frac{\partial}{z}\left(\mu \frac{\partial v}{\partial z}\right)-\frac{\partial p}{\partial y}+F_{y} \\
& \frac{\partial(\rho w)}{\partial t}+\frac{\partial(\rho w u)}{\partial x}+\frac{\partial(\rho w v)}{\partial y}+\frac{\partial(\rho w w)}{\partial z}=\frac{\partial}{x}\left(\mu \frac{\partial w}{\partial x}\right)+\frac{\partial}{y}\left(\mu \frac{\partial w}{\partial y}\right)+\frac{\partial}{z}\left(\mu \frac{\partial w}{\partial z}\right)-\frac{\partial p}{\partial z}+F_{z}
\end{aligned}
$$

Formula t expresses time, u expresses velocity vector, $u, v, w$, respectively, for the in and, component in the direction of; $\mathrm{p}$ expresses the density of water, $\mathrm{Pa}$; coefficient of dynamic viscosity; - fluid element body pressure; and, element quality. If the mass force is only the gravity and the shaft is vertical upward, then the shaft is 0,0 , and $-\rho g, \mathrm{~N}$.

For incompressible flow, turbulent kinetic energy and dissipation rate epsilon kappa transport equation:

$$
\begin{aligned}
& \frac{\partial(\rho k)}{\partial t}+\frac{\partial\left(\rho k u_{i}\right)}{\partial x_{i}}=\frac{\partial}{\partial x_{j}}\left[\left(\mu+\frac{\mu_{t}}{\sigma_{k}}\right) \frac{\partial k}{\partial x_{j}}\right]+G_{k}-\rho \varepsilon \\
& \frac{\partial(\rho \varepsilon)}{\partial t}+\frac{\partial\left(\rho \varepsilon u_{i}\right)}{\partial x_{i}}=\frac{\partial}{\partial x_{j}}\left[\left(\mu+\frac{\mu_{t}}{\sigma_{\varepsilon}}\right) \frac{\partial \varepsilon}{\partial x_{j}}\right]+\frac{C_{1 \varepsilon} \varepsilon}{k} G_{k}-C_{2 \varepsilon} \rho \frac{\varepsilon^{2}}{k}
\end{aligned}
$$

In the formula: $\mu_{t}$ - the turbulence viscosity, $G_{k}$ express the generation of turbulent kinetic energy caused by the average velocity gradient, $C_{1 \varepsilon}, C_{2 \varepsilon}, \sigma_{k}, \sigma_{\varepsilon}$ express, the empirical constant, $C_{1 \varepsilon}=1.44, C_{2 \varepsilon}=1.92, \sigma_{k}=1, \sigma_{\varepsilon}=1.3^{[4]}$.

As the results of some domestic scholars' researches, the water flow in this kind of labyrinth channel drip irrigation emitter is turbulence flow. Therefore this paper uses k- $\varepsilon$ turbulence model for simulating.

Accuracy 0.0001 is selected for the simulation. The inlet of the channel is set as the pressure inlet, and the outlet is set as the pressure outlet for boundary condition. Standard wall function method is applied to the inner wall of the flow channel.

\section{Numerical simulation results}

Import MSH file into Fluent solver, load physical properties and boundary conditions. 2000 iterations, the general in the 1000 or so can be convergent. Simulated flow value per time unit $\mathrm{q}_{\mathrm{m}}(\mathrm{kg} / \mathrm{s})$. The unit is then converted into $1 / \mathrm{h}$.

The simulating results for the 8 types of emitter channel in Table 1.1 are in Table $4-1$ and regression curves are in Figure 4-2 and 4-3 which based on the condition of 10KPa per step between 10 100 Kpa pressure. From simulation results, we can see such a design of emitter flow channel having a better performance as design required that output flows are all in the range of about 21/h when under the water pressure 5 meters while the values of index $x$ to $h$ (the sensitive coefficient to pressure various) are all under 0.5 and the minimum area of flow is bigger than the sensitive dimension $0.2 \mathrm{~mm}^{2}$ which are pretty good for such type of turbulence water emitters. Therefore, top 6 designs of 8 are selected for trail sample manufacturing.

\section{Inclined tooth micro pressure drip emitter prototyping}

We chose six kinds channel to make into samples, and its kind shown in figure 3-1

After the trial samples manufactured, we measure the samples' channel shapes and dimensions. under micro scope. The samples dimensions are shown on Table 3-1

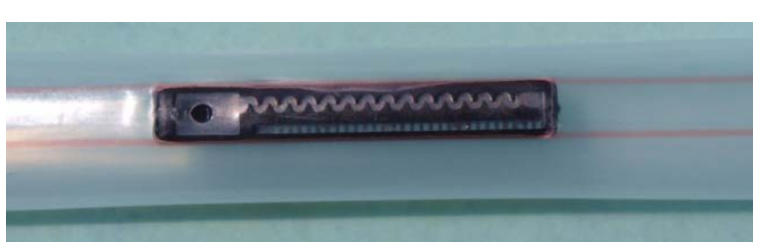

Figure 3-1 Emitter sample 
Table 3-1 the geometric dimensioning of flaky Dripper first trial product

\begin{tabular}{|c|c|c|c|c|c|c|c|c|}
\hline \multirow{2}{*}{$\begin{array}{l}\text { Numerical } \\
\text { Order }\end{array}$} & \multirow{2}{*}{$\begin{array}{l}\text { Serial } \\
\text { Number }\end{array}$} & \multicolumn{2}{|c|}{ Depth (mm) } & \multicolumn{2}{|c|}{$\begin{array}{l}\text { Minimum Channel } \\
\text { Breadth (mm) }\end{array}$} & \multicolumn{2}{|c|}{$\begin{array}{l}\text { Minimum Cross Section } \\
\left(\mathrm{mm}^{2}\right)\end{array}$} & \multirow[t]{2}{*}{ Error } \\
\hline & & Measured & Design & Measured & Design & Measured & Design & \\
\hline 1 & JJ9r0.8 & 0.7719 & 0.75 & 0.7515 & 0.72 & 0.5801 & 0.54 & $7 \%$ \\
\hline 2 & JJ15r0.8 & 0.7609 & 0.75 & 0.7343 & 0.7 & 0.5587 & 0.525 & $6 \%$ \\
\hline 3 & JY0r0.3 & 0.7480 & 0.75 & 0.7506 & 0.76 & 0.5614 & 0.57 & $-1.5 \%$ \\
\hline 4 & JY5r0.5 & 0.7774 & 0.75 & 0.7649 & 0.76 & 0.5946 & 0.57 & $4 \%$ \\
\hline 5 & JY10r0.8 & 0.7802 & 0.75 & 0.7977 & 0.75 & 0.6224 & 0.563 & $10 \%$ \\
\hline 6 & JY15r0.8 & 0.7675 & 0.75 & 0.7581 & 0.73 & 0.5818 & 0.548 & $6 \%$ \\
\hline
\end{tabular}

\section{Sample Performance Experiment of Drip Irrigation Tape}

\section{A Test Purpose}

To determine flow under different pressure on trial samples of 6 types of drip irrigation tapes, in this paper, regression analysis on relationship between flow and pressure is undertaken and the results are compared with the simulation results of CFD to evaluate the differences of simulation output; When evaluating hydraulic performance of each drip irrigation tape flow channel structure, the hydraulic performance of each drip irrigation tape under the condition of micro pressure is emphasized to determine better performance on various structure, thereby determining the most significant impact structure parameters.

\section{B Test Basis}

The design of test scheme reference for 《National Standard of the People's Republic of China Agricultural irrigation equipment-Emitters and emitting pipe-Specification and test methods》 (GB/T 17187-2009) and 《Professional Standard of the People’s Republic of China Micro-irrigation emitters-micro tubings 、 micro tapes》(SL/T67.2-94)。

\section{$\mathrm{C}$ Test Equipments and Instruments}

Tests are performed in hydraulics laboratory of the Hohai University and test system is designed and installed solely for the drip irrigation tape testing. The diagram is shown in figure 4-1.

\section{Test Methods and Steps}

With single factor test method five randomly are selected drip irrigation tape trial sample (each containing five outlet). Samples with dead end are horizontally placed on the test table. During the test, drip flow of each outlet under the different pressure is measured at very beginning and then drip irrigation belt samples are tested on the 25 outlet by measuring the output water flow under the different pressure. Repeating two times with each taken about 10 minutes, the difference of water amount between two measurements should not be greater than $2 \%$, and then take the average value as the final result.

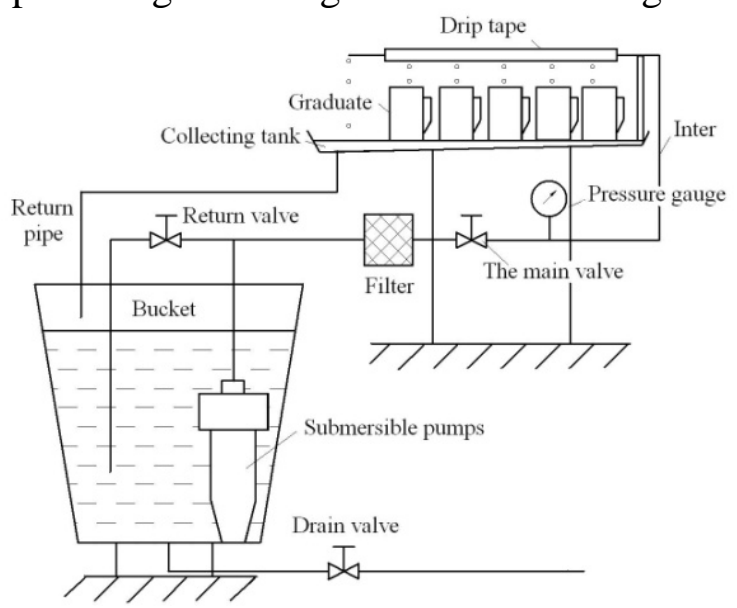

Figure 4-1 Schematic diagram of drip irrigation tape performance test rig

According to the measured flow data of 25 outlet, number according to the ascending order, No. 3, 12, 13 and 23 are selected. 14 pressure points are distributed within $5 \sim 100$ kpa pressure according to the ascending order. Measure flow data of each outlet under the pressure point, repeat three times, each measure time is $10 \mathrm{~min}$, the difference between two measured the amount of water is not greater than $2 \%$,take the average value as the measured flow.

\section{E Test Results and Analysis}

The relational expression between the emitter flow and pressure is:

$$
\mathrm{q}=\mathrm{kh}^{\mathrm{x}}
$$


Where, q-Emitter flow (L / h); h-Working head of emitter(m); k-Discharge coefficient of emitter (related to the geometry size); $\mathrm{x}$-Flow stance index of emitter 。

The above index model is used to simulate the relationship between flow and pressure regression analysis, producing six kinds of relationship curves between flow and pressure of drip irrigation tape in the whole pressure area and micro-pressure area. Compared to before the CFD simulation results, comparative table of six type numerical simulation and indoor testing are completed, as shown in table 4-1 and table 4-2. Eight kinds of curve of analog regression as shown in figure 4-2, 4-3, 6 kinds of regression curve of physical test as shown in figure 4-4,4-5.

\section{Analysis of the experiment and simulation results:}

(1) From the table 4-1 and table 4-2; Figure 4-2, 4-5, the regression equation R2 are greater than 0.996 . It showed better fitting degree of regression equation.

Table 4-1 The comparison between numerical simulation and laboratory test of six new type drip irrigation tape inverse tooth (the whole pressure area)

\begin{tabular}{|c|c|c|c|c|}
\hline \multirow{2}{*}{$\begin{array}{l}\text { Drip irrigation } \\
\text { tape type }\end{array}$} & \multicolumn{2}{|c|}{ The whole pressure area $(5 \sim 100 \mathrm{kPa})$} & \multirow{2}{*}{$\begin{array}{c}\mathrm{K} \\
\text { error \% }\end{array}$} & \multirow{2}{*}{$\begin{array}{c}\mathrm{X} \\
\text { error\% }\end{array}$} \\
\hline & CFD simulation & Physical test & & \\
\hline 1/JJ9r0.8 & $\mathrm{q}_{1}=0.3066 \mathrm{~h}^{0.4919} \mathrm{R}^{2}=0.9999$ & $\mathrm{q}_{1}=0.2958 \mathrm{~h}^{0.4886} \mathrm{R}^{2}=0.9996$ & -3.5 & -0.7 \\
\hline 2/JJ15 r 0.8 & $\mathrm{q}_{2}=0.3084 \mathrm{~h}^{0.4937} \mathrm{R}^{2}=1$ & $\mathrm{q}_{2}=0.2938 \mathrm{~h}^{0.4946} \mathrm{R}^{2}=0.9995$ & -4.7 & 0.2 \\
\hline 3/JY0 r 0.3 & $\mathrm{q}_{3}=0.3075 \mathrm{~h}^{0.4875} \mathrm{R}^{2}=1$ & $\mathrm{q}_{3}=0.2713 \mathrm{~h}^{0.4866}$ & -11.8 & -0 . \\
\hline $4 / J Y 5$ & $\mathrm{q}_{4}=0.3089 \mathrm{~h}^{0.4878} \mathrm{R}^{2}=1$ & $\mathrm{q}_{4}=0.2809 \mathrm{~h}^{0.4939} \quad \mathrm{R}^{2}=0.9995$ & -9.1 & 1.3 \\
\hline 5/JY10 r 0.8 & $\mathrm{q}_{5}=0.3088 \mathrm{~h}^{0.4899} \mathrm{R}^{2}=1$ & $\mathrm{q}_{5}=0.2969 \mathrm{~h}^{0.4953} \mathrm{R}^{2}=0.9995$ & -3.9 & 1.1 \\
\hline 6/JY15 r 0.8 & $\mathrm{q}_{6}=0.3097 \mathrm{~h}^{0.4905} \mathrm{R}^{2}=0.9999$ & $\mathrm{q}_{6}=0.2938 \mathrm{~h}^{0.5037} \quad \mathrm{R}^{2}=0.9996$ & -5.1 & 2.7 \\
\hline 7/JY15r0.5 & $\mathrm{q}_{7}=0.3045 \mathrm{~h}^{0.4916} \mathrm{R}^{2}=1$ & & & \\
\hline 8/JY15 r 0.3 & $\mathrm{q}_{8}=0.3043 \mathrm{~h}^{0.4904} \mathrm{R}^{2}=1$ & & & \\
\hline
\end{tabular}

Table 4-2 The comparison between numerical simulation and laboratory test of six new type drip irrigation tape inverse tooth (the micro-pressure area)

\begin{tabular}{|c|c|c|c|c|}
\hline \multirow{2}{*}{$\begin{array}{l}\text { Drip irrigation } \\
\text { tape type }\end{array}$} & \multicolumn{2}{|c|}{ The micro-pressure area $\quad(5 \sim 50 \mathrm{kPa})$} & \multirow{2}{*}{$\begin{array}{c}\mathrm{K} \\
\text { error \% }\end{array}$} & \multirow{2}{*}{$\begin{array}{c}\mathrm{X} \\
\text { error \% }\end{array}$} \\
\hline & CFD simulation & Physical test & & \\
\hline 1/JJ9R0.8 & $\mathrm{q}_{1}=0.3035 \mathrm{~h}^{0.4952} \mathrm{R}^{2}=0.9999$ & $\mathrm{q}_{1}=0.3043 \mathrm{~h}^{0.4794} \mathrm{R}^{2}=0.9995$ & -0.3 & -3.2 \\
\hline 2/JJ15R0.8 & $\mathrm{q}_{2}=0.3066 \mathrm{~h}^{0.4956} \mathrm{R}^{2}=0.9999$ & $\mathrm{q}_{2}=0.2989 \mathrm{~h}^{0.489} \mathrm{R}^{2}=0.9991$ & -2.5 & -1.3 \\
\hline 3/JY0R0.3 & $\mathrm{q}_{3}=0.3053 \mathrm{~h}^{0.4898} \quad \mathrm{R}^{2}=1$ & $\mathrm{q}_{3}=0.2776 \mathrm{~h}^{0.4792} \mathrm{R}^{2}=0.9996$ & -9.1 & -2.2 \\
\hline 4/JY5R0.5 & $\mathrm{q}_{4}=0.3071 \mathrm{~h}^{0.4898} \mathrm{R}^{2}=0.9999$ & $\mathrm{q}_{4}=0.2899 \mathrm{~h}^{0.4837} \mathrm{R}^{2}=0.9995$ & -5.6 & -1.2 \\
\hline 5/JY10R0.8 & $\mathrm{q}_{5}=0.3072 \mathrm{~h}^{0.4915} \mathrm{R}^{2}=0.9999$ & $\mathrm{q}_{5}=0.3081 \mathrm{~h}^{0.4833} \mathrm{R}^{2}=0.9998$ & 0.3 & -1.7 \\
\hline 6/JY15R0.8 & $\mathrm{q}_{6}=0.3077 \mathrm{~h}^{0.4925} \mathrm{R}^{2}=0.9999$ & $\mathrm{q}_{6}=0.3023 \mathrm{~h}^{0.4944} \mathrm{R}^{2}=0.9997$ & -1.8 & 0.4 \\
\hline 7/JY15R0.5 & $\mathrm{q}_{7}=0.3027 \mathrm{~h}^{0.4935} \mathrm{R}^{2}=1$ & & & \\
\hline 8/JY15R0.3 & $\mathrm{q}_{8}=303 \mathrm{~h}^{0.4918} \quad \mathrm{R}^{2}=1$ & & & \\
\hline
\end{tabular}

(2) The flow index $\mathrm{k}$ and flow coefficient $\mathrm{x}$ of the CFD simulation result are close to the laboratory test results. But $\mathrm{k}$ values is larger One of the reasons is difference between the theory analysis (simulation) and the real cases. Another is manufacturing accuracy. From the table 3-1 it can be seen that the error of the minimum cross section are no less than $4 \%$ except No.3, but the error of the flow coefficient is small. That indicates that the turbulent flow type emitters with such a micro scale channel are very sensitive. For the parameter $x$, the error is not more than $4 \%$ under the condition of the size of the minimum flow channel changing from $-10 \%$, to $+10 \%$. This means that the flow stance index is not affected significantly when the flow channel size changed and X mainly depends on the structure of flow channel. By overall, using CFD theatrical simulation during irrigation emitter design will have a very good result that can reduce design time and the manufacture cost by predicting the product performance with an effective way.

(3) Compared with JJ series 1 and 2, it can be concluded that under the same size of chamfering $r$, the smaller the angle $\theta$ between tooth its flow index $\mathrm{x}$ is, the better performance as a small flow stance index $\mathrm{x}$ indicates that flow along with pressure change is small and water flow is 
more stable.

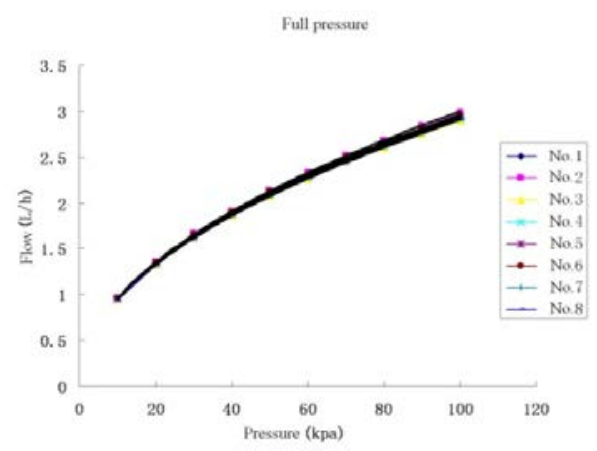

Figure 4-2 the theoretical simulation curve of eight new type drip irrigation tape inverse tooth in the full pressure area

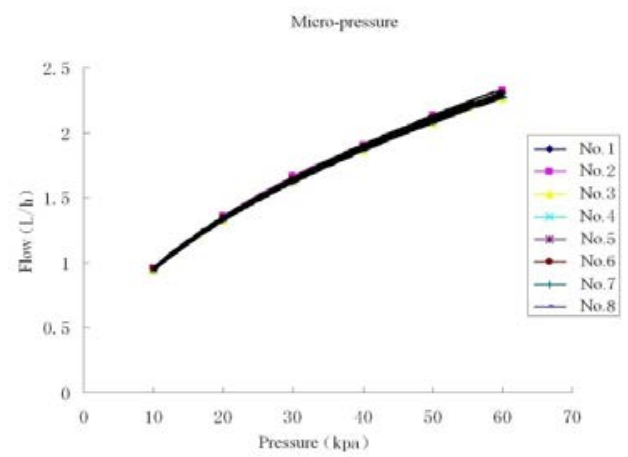

Figure 4-3 the theoretical simulation curve of eight new type drip irrigation tape inverse tooth in the micro- pressure area

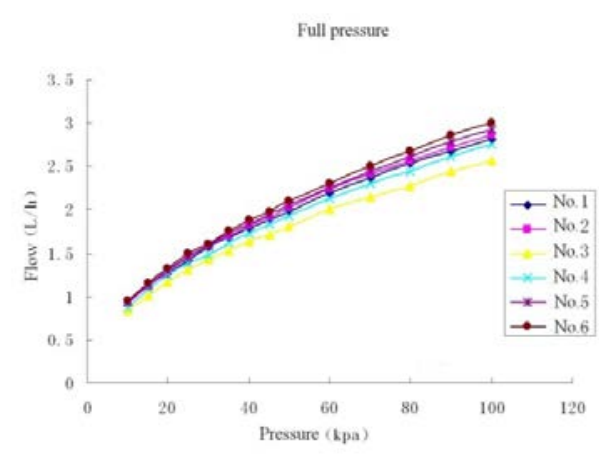

Figure 4-4 the laboratory test curve of six new type drip irrigation tape inverse tooth in the full pressure area

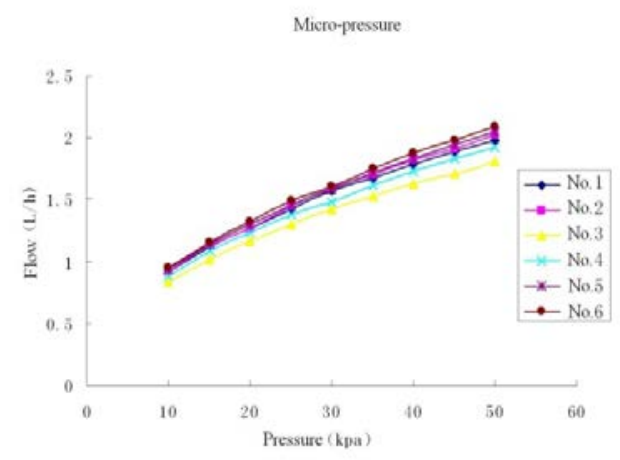

Figure 4-5 The laboratory test curve of six new types drip irrigation tape with inverse tooth in the micro-pressure area

(4) Compared with JY series, it can be concluded that increasing the angle between tooth $\theta$ and chamfering $\mathrm{r}$ can make flow stance index $\mathrm{x}$ increased even under the same chamfering $\mathrm{r}$. From table 4.1, 4.2, it can be seen that with the same tooth angle the reducing the angle of tooth root chamfering will make flow stance index distressing. However with analysis results on distribution of 2.3 flow pressure and velocity, the bigger chamfering will reduce back water vortex area and therefore reduce the chance of particles staying which will increase anti-clogging ability. Thus the root chamfering $\mathrm{r}$ should not be too small.

(5) In general, for JJ series and JY series (considering the impacts on test data with test errors and irrigation emitter manufacturing errors), it can be predicted that the flow index $\mathrm{x}$ will increase when increasing tooth angle $\theta$ on inverse tooth, even with same chamfering $\mathrm{r}$.

(6) Compared with JJ series and JY series, it can be concluded that both have the almost same flow index $\mathrm{x}$ for No.2 and No.6 which have the same chamfering $\mathrm{r}$ and tooth angle $\theta$. Under theoretical simulation JY's flow index $\mathrm{x}$ is slightly smaller while under real trial sample test the result is opposite. Under theoretical simulation JJ's flow index x of No.1 and No.5 with similar tooth angle $\theta$ and the same chamfering $r$ is significantly bigger than JY's, but real sample test shows reverse result. This is due to the error between theoretical design modeling and production and also the number of levels is less. By ignoring the impacts of chamfering $r$, the flow index $\mathrm{x}$ is minimum when the tooth angle $\theta$ of JY series equal to $0^{\circ}$. It suggests that the $\mathrm{x}$ value of along tooth may be less than the inverse tooth and we will study flow with along the tooth in the future.

(7) On whole area with pressure, the flow index $x$ of the drip irrigation belt under micro pressure are all slightly higher than that of other area and that can suggest that the lower the pressure the harder to control the performance, which will make it more difficult to design a high performance irrigation emitters with the low pressure. 


\section{Conclusion}

(1) Based analysis results on 8 kinds of theoretical simulation and 6 kinds of new trial samples of drip irrigation belts, it can be seen that CFD simulation result is very close to the real sample test and the result can be used to predict the performances of hydraulic performance of drip irrigation emitters.

(2) The flow index $x$ on both JJ Series and Y Series are reducing when angle $\theta$ teeth decreases which indicates that along tooth having a better performance than that of inverted tooth. That can be new research topic for the future.

(3) Although larger chamfering $r$ has a slight negative impact to flow index $x$ it can improve anti-clogging performance. Considering majority of clogging failures happening in the rear part of emitters in the fields, a larger tooth root chamfer or semi-circular boundary should still be used to improve anti-clogging performance of emitters.

(4) A small change on the channel size will lead a great impact on flow but have a slight impact on flow index $\mathrm{x}$. as flow index $\mathrm{x}$ depends on emitter structure. It is a long and arduous task to study a better performance emitter structure.

(5) All flow index $x$ of drip irrigation belt under micro pressure zone are slightly higher than that with full pressure. It indicates that designing and manufacturing a better performance of micro-pressure emitters are more difficult than that with full pressure. In this paper, all emitters are studied with low index $\mathrm{x}$ which less than 0.5 ,and some of them only 0.4792 with minimum cross-sectional area greater than $0.55 \mathrm{~mm}^{2}$. This structure with the largest possible flow cross-section and less flow has better hydraulic performance and anti-clogging properties.

\section{Acknowledgements}

Project supported by the National 863 high technology research and development program funded project (2006AA100214-7); AND Jiangsu Province 2013 agricultural Sanxin Engineering: intelligent micro irrigation system and its key technology (NJ2013-16) development; AND Jiangsu Province 2014 plan scientific and technological support: intelligent agriculture of high performance of drip irrigation, micro spray technology products development (BE2014409).

\section{Reference}

[1]Shen Ruibao, Wang Guowu. Study on the efficiency of agricultural water use in the Journal of Shandong Water Polytechnic, 2006, (3).

[2] Niu Wenquan, Wu pute, van Xingke. Micro Pressure Drip Irrigation Technology Theory and Feasibility Analysis [C]. Agricultural Engineering in China learn 2005 annual academic conference proceedings.2005:282 287

[3]Zhou Heping, Deng Ming Zhao, Yu Feng. Water-saving irrigation device research status and Prospect of China [J]. China rural water and hydropower 2007 (5): 68-70

[4] Sun Yanling, Experimental Study On The Micro Pressure Drip Irrigation Emitter [D]. Nanjing: Hohai University, 2008

[5] Fang Buling et al. One Kind of Inclined Tooth Ddrip Irrigation Emitter [P]. Nanjing: Hohai University, 2009

[6]Wang Fujun, Computational Fluid Dynamics Analysis -- CFD Software Principle and Application [M]. Beijing: Tsinghua University press, 2004.9.

[7] Wang Ruijin, Zhang Kai, Wang Gang. FLUENT Technology and Application Examples [M]. Beijing: Tsinghua University press, 2007.2:50 67

[8] Qi Songtao, anti clogging rahfu test of micro pressure drip irrigation for the Nanjing based [D]. research: Hohai University, 2009 